\title{
Methuselah's Diary and the Finitude of the Past
}

\author{
BEN WATERS \\ Department of Mathematics \\ Rice University \\ Houston, Texas
}

There is no reason to suppose that the world had a beginning at all. The idea that things must have a beginning is really due to the poverty of our imagination. Therefore, perhaps, I need not waste any more time upon the argument about the First Cause.

Bertrand Russell, "Why I Am Not a Christian"

In a now well-known example, Bertrand Russell considered the case of Tristram Shandy, a character in a novel by Sterne who works on his autobiography at such a slow pace that it takes him one year to finish recording the history of a single day of his life. ${ }^{1}$ Regardless of when Tristram Shandy starts working on his autobiography it will not be finished at the time of his death, as new material for his autobiography will accumulate at a faster rate than he can record it. However, if, as Russell additionally supposes, Tristram Shandy will not die, and will not cease from working on his autobiography, then it follows that each day finitely distant in the future from his birth will eventually be recorded in spite of the fact that Tristram Shandy is continually falling behind in his work.

More recently, Russell's example has been ingeniously modified by William Lane Craig for the purposes of demonstrating the finitude of the past. ${ }^{2}$ In particular, Craig modified Russell's example by supposing instead that Tristram Shandy has been recording consecutive past days in his autobiogra-

ABSTRACT: William Lane Craig modified Bertrand Russell's Tristram Shandy example in order to derive an absurdity that would demonstrate the finitude of the past. Although his initial attempt at such an argument faltered, further developments in the literature suggested that such an absurdity was indeed in the offing provided that a couple extra statements were also shown to be true. This article traces the development of a particular line of argument that arose from Craig's Tristram Shandy example before advancing an argument of its own that attempts to fill in the relevant gaps so as to yield a new argument for the finitude of the past.

1. Bertrand Russell, The Principles of Mathematics (London: Clay and Sons, 1903), 358-9.

2. William Lane Craig, The Kalām Cosmological Argument (London: Macmillan, 1979), 98-9. 
phy at a rate of one day per year from "eternity past." Craig maintained that in this case absurdities would result that disprove the possibility of an infinite past, arguing as follows:

But let us turn the story about: suppose Tristram Shandy has been writing from eternity past at the rate of one day per year. Would he now be penning his final page? Here we discern the bankruptcy of the principle of correspondence in the world of the real. For according to that principle, Russell's conclusion would be correct: a one-to-one correspondence between days and years could be established so that given an actual infinite number of years, the book will be completed. But such a conclusion is clearly ridiculous, for Tristram Shandy could not yet have written today's events down. In reality he could never finish, for every day of writing generates another year of work. But if the principle of correspondence were descriptive of the real world, he should have finished - which is impossible.

... But now a deeper absurdity bursts into view. For if the series of past events is an actual infinite, then we may ask, why did Tristram Shandy not finish his autobiography yesterday or the day before, since by then an infinite series of events had already elapsed? No matter how far along the series of past events one regresses, Tristram Shandy would have already completed his autobiography. Therefore, at no point in the infinite series of past events could he be finishing the book. We could never look over Tristram Shandy's shoulder to see if he were now writing the last page. For at any point an actual infinite sequence of events would have transpired and the book would have already been completed. Thus, at no time in eternity will we find Tristram Shandy writing, which is absurd, since we supposed him to be writing from eternity. And at no point will he finish the book, which is equally absurd, because for the book to be completed he must at some point have finished. What the Tristram Shandy story really tells us is that an actually infinite temporal regress is absurd. ${ }^{3}$

Although the precise details of Craig's argument are somewhat difficult to discern, it is clear that he thinks that for any day finitely distant in the past Tristram Shandy should be expected to have "finished" writing in his autobiography since for any such day Tristram Shandy will have been writing in his autobiography for an infinite collection of years that can be put in a one-toone correspondence with the infinite collection of prior days finitely distant in the past in which he has lived. But then it follows that Tristram Shandy will not be writing in his autobiography in any day finitely distant in the past, which, as Craig observes, contradicts the fact that "we supposed him to be writing from eternity."

Unfortunately, this line of argument suffers from its dependence on the assumption that Tristram Shandy should be expected to have written about 
every day finitely distant in the past simply because he has been writing for an infinite collection of years that can be put in a one-to-one correspondence with the former collection of days. In particular, why on any such day couldn't Tristram Shandy have only written about an infinite proper subcollection of the days in which he has lived? After all, unlike finite collections, the elements of an infinite collection can always be put in a one-to-one correspondence with those of a proper sub-collection. Hence, it seems that this assumption requires further justification that Craig does not provide. Similarly, Richard Sorabji, David Conway, and Quentin Smith have all criticized Craig's argument along nearly identical lines $;{ }^{4}$ however, it should be noted that their objections have not gone unanswered by Craig. ${ }^{5}$

In any case, a less problematic approach to deriving an absurdity from Craig's example was later found by Robin Small. ${ }^{6}$ Small observed that if Tristram Shandy has been recording consecutive past days at a rate of one day per year then it follows that Tristram Shandy is always falling behind 364 days for every year (that is, 365 days) of work. Therefore, if Tristram Shandy has been working on his autobiography for at least one year then it follows that the most recent day he could be writing about today would be 364 days ago. Similarly, if he has been working on his autobiography for at least two years then it follows that the most recent day he could be writing about today would be $(364+364)$ days ago, and so on. ${ }^{7}$ Hence, if Tristram Shandy has been working on his autobiography from eternity past then it follows that today he must be writing about a day that is infinitely distant in the past. Consequently, all that remains to demonstrate an absurdity in the case of Craig's example is to show that there are no infinitely distant past days.

However, even if an argument is given to demonstrate that there are no infinitely distant past days, the absurdity that would follow from Small's analysis is still not enough to demonstrate that the past is necessarily finite. For as noted by Wes Morriston, such an argument would have to proceed as follows: ${ }^{8}$

4. Richard Sorabji, Time, Creation, and the Continuum: Theories in Antiquity and the Early Middle Ages (Ithaca, NY: Cornell University Press, 1983), 222; David Conway, "It Would Have Happened Already: On One Argument for a First Cause," Analysis 44 (1984): sec. 3; Quentin Smith, "Infinity and the Past," Philosophy of Science 54 (1987): sec. 4.

5. William Lane Craig, critical notice of Time, Creation, and the Continuum, International Philosophical Quarterly 25 (1985): 319-26; William Lane Craig and Quentin Smith, Theism, Atheism, and Big Bang Cosmology (Oxford: Oxford University Press, 1993), 99-106; Paul Copan and William Lane Craig, Creation out of Nothing: A Biblical, Philosophical, and Scientific Exploration (Grand Rapids, MI: Baker Academic, 2004), 215-16.

6. Robin Small, "Tristram Shandy's Last Page," British Journal for the Philosophy of Science 37 (1986): 215-16.

7. The calculations allow for the possibility that Tristram Shandy can write about the same day on which he began working on his autobiography (e.g., Tristram Shandy writes in the evening about things that happened earlier in the day).

8. Wes Morriston, "Must the Past Have a Beginning?," Philo 2 (1999): sec. 3. 
(1) If the past were infinite then it is possible that Tristram Shandy could have been recording consecutive past days at a rate of one day per year from eternity past.

(2) It is not possible that Tristram Shandy could have been recording consecutive past days at a rate of one day per year from eternity past.

(3) Therefore, the past is not infinite by (1) and (2).

Hence, the more significant difficulty with Craig's argument, or a similar argument that proceeded along the lines of Small's analysis, is that even if it succeeds in demonstrating that Tristram Shandy could not possibly have been recording consecutive past days at a rate of one day per year from eternity past it still remains to show (1), which is to say that Tristram Shandy should have been able to have done so given an infinite past. As Morriston observes, whatever absurdity one might find in Craig's example can be resolved just as easily by denying (1) as it can by denying that the past is infinite. ${ }^{9}$ But how could one show that Craig's example should be possible if, in fact, it isn't possible? It seems that the requisite analysis would have to thread a very small needle. In any case, it is not enough to simply assert that the relevant scenario is "obviously coherent." ${ }^{10}$ Morriston's point has gone unanswered.

Craig's modification of Russell's example has inspired a literature of its own. ${ }^{11}$ The reason for this was aptly stated by Conway, "[other] arguments for the crucial premise that an infinite regress is impossible do little more than point out that infinite series have odd properties" but "[this argument] is supposed to show that the hypothesis of an infinite regress leads not just to 'oddities' but to real contradictions." 12 In the next section I will attempt to thread the aforementioned needle by arguing for the finitude of the past along lines similar to those explored in this introduction.

\section{Methuselah's Diary}

I first introduce some notation. Let $t$ represent today, $D$ the collection of all days prior to $t, \leq$ the total relation on $D$ where $d_{1} \leq d_{2}$ if and only if $d_{1}$ is earlier than or the same as $d_{2}$, and $=$ the relation on $D$ where $d_{1}=d_{2}$ if and only if $d_{1} \leq d_{2}$ and $d_{2} \leq d_{1}$ (that is, $d_{1}$ is the same as $d_{2}$ ). Furthermore, for any $d$ in $D$ and any positive integer $n$ such that $d$ precedes $t$ by at least $(n+1)$ days let $(d+n)$ represent the unique $n$th day following $d$ in $D$; similarly, if

9. Ibid.

10. Copan and Craig, Creation out of Nothing, 214.

11. See also David S. Oderberg, "Traversal of the Infinite, the 'Big Bang' and the Kalām Cosmological Argument," Philosophia Christi 4 (2002): 305-34; Graham Oppy, "The Tristram Shandy Paradox: A Response to David S. Oderberg," Philosophia Christi 4 (2002): 335-49.

12. Conway, "It Would Have Happened Already," 159. 
$d$ does not follow a possible earliest day of $D$ by less than $n$ days let $(d-n)$ represent the unique $n$th day preceding $d$ in $D .{ }^{13}$ Finally, let $D_{F}$ represent the subcollection of all days in $D$ that are finitely distant in the past so that $D_{F}$ only contains those days in $D$ that are of the form $(t-m)$ for some positive integer $m$ and not any possible days in $D$ that are infinitely distant in the past.

With these conventions in mind, the argument is given as follows:

(1) If there exists a function $f$ from $D_{F}$ to $D_{F}$ such that $f(d) \leq d$ for any $d$ in $D_{F}$ and $f(d+2)=(f(d)+1)$ for any pair $d,(d+2)$ in $D_{F}$ then $D$ is finite.

(2) There exists a function $f$ from $D_{F}$ to $D_{F}$ such that $f(d) \leq d$ for any $d$ in $D_{F}$ and $f(d+2)=(f(d)+1)$ for any pair $d,(d+2)$ in $D_{F}$.

(3) Therefore, $D$ is finite by (1) and (2).

I establish (1) by first noticing that $D_{F}$ is either a finite collection with an earliest day or the infinite collection $\{(t-n) \mid n$ is any positive integer $\}$ and assume that there exists a function $f$ from $D_{F}$ to $D_{F}$ such that $f(d) \leq d$ for any $d$ in $D_{F}$ and $f(d+2)=(f(d)+1)$ for any pair $d,(d+2)$ in $D_{F}$. Suppose $D_{F}$ can be identified with the aforementioned infinite collection and observe that $f(t-1)=(t-m)$ for some positive integer $m$. It follows that $(t-m)=f(t-1)$ $=f((t-(1+2 m))+2 m)=(f(t-(1+2 m))+m)$ so that $f(t-(1+2 m))=(t-$ $2 m)$, which contradicts the fact that $f(t-(1+2 m)) \leq(t-(1+2 m))$. Hence, $D_{F}$ cannot be the aforementioned infinite collection so that it is a finite collection with an earliest day $e$. Now, if $e$ is not also an earliest day of $D$ then it has a previous day $(e-1)$ in $D_{F}$, which contradicts the fact that $e$ is the earliest day of $D_{F}$. Hence, $e$ is not only the earliest day of $D_{F}$ but also the earliest day of $D$. However, if $D$ has an earliest day that is finitely distant in the past then it follows that $D$ is finite so that (1) is established.

I now establish (2) by considering the case of Methuselah, who has been alive for every $d$ in $D_{F}$ and is the oldest living individual. More pertinently, Methuselah has maintained a diary of his previous activities throughout his long life; however, he only works on entries for his diary in the evenings and never on more than one entry per day, with each entry summarizing his past activities for some $d$ in $D_{F}$. Additionally, for any pair $(d-1), d$ in $D_{F}$ Methuselah has a perfect memory on $d$ of everything he did on $(d-1)$ and whenever he works on an entry for his diary it is always at a rate of half an entry per day. With these stipulations in mind, Methuselah works on entries for his diary in the following manner:

For any $d$ in $D_{F}$, if Methuselah remembers working on an entry for $(d-m)$ on a previous day $(d-1)$ for some positive integer $m$ then in the evening he will continue working on his diary where he had left off at the end of $(d-1)$. In particular, if Methuselah had not finished working on an entry for $(d-m)$ then he will continue working on 
that entry, otherwise he will start working on an entry for $((d-m)+$ 1). On the other hand, if Methuselah does not remember working on such an entry on a previous day $(d-1)$ then in the evening he will start working on an entry for $d .{ }^{14}$

Finally, I remark that Methuselah is thought of as belonging to a logically possible world that shares all the relevant temporal facts with the actual world.

It follows that for any $d$ in $D_{F}$ Methuselah will work on an entry for either $d$ or one of $(d-m),((d-m)+1)$ for some positive integer $m$, but in any case he will work on an entry for a day in $D_{F}$ that is earlier than or the same as $d$. Hence, there exists a function $f$ from $D_{F}$ to $D_{F}$ such that $f\left(d_{1}\right)=d_{2}$ if and only if Methuselah works on an entry for $d_{2}$ on $d_{1}$ for any $d_{1}, d_{2}$ in $D_{F}$ with $f(d) \leq d$ for any $d$ in $D_{F}$. Finally, I observe that $f(d+2)=(f(d)+1)$ for any pair $d,(d+2)$ in $D_{F}$ since Methuselah always takes two consecutive days to finish writing an entry for his diary and he always works on subsequent days where he had left off at the end of previous days given his memory and the manner in which he works on entries for his diary in the evening of every $d$ in $D_{F}$. Hence, $f$ satisfies all the conditions needed to establish (2).

\section{Remarks}

In commenting on the previous argument I first remark that it is obviously valid and entails the finitude of the past. Secondly, I remark that the previous argument resolves the primary deficiency of the line of argument explored in the introduction by constructing a logically possible scenario concerning the diary-keeping activities of Methuselah that is for all intents and purposes equivalent to Craig's example concerning the autobiographical activities of Tristram Shandy. Thirdly, I remark that what distinguishes the previous argument for the finitude of the past from other such arguments is that it proceeds via the existence of a particular function from the collection of all days finitely distant in the past to itself that is incompatible with an infinite past. In particular, other approaches to demonstrating the finitude of the past in classical thought have typically proceeded along more general lines, such as the metaphysical impossibility of forming an infinite collection by successive addition or even the metaphysical impossibility of infinite collections themselves. ${ }^{15}$ Fourthly, in contrast with those efforts, the previous argument perhaps enjoys a reduced risk of proving too much while taking place at the level of what is logically possible and not the more difficult level of what is metaphysically possible. Finally, I remark that the previous argu-

14. This would include the case where $d$ does not have a previous day $(d-1)$ in $D$.

15. See William Lane Craig, "Whitrow and Popper on the Impossibility of an Infinite Past," British Journal for the Philosophy of Science 30 (1979): sec. 1. 
ment can be naturally generalized to apply to arbitrary countable sequences of temporal intervals $\left\{I_{1}, I_{2}, I_{3}, \ldots\right\}$ that recede into the past (that is, $I_{2}$ is earlier than $I_{1}, I_{3}$ is earlier than $I_{2}$, and so on). It follows that all such sequences must, in fact, be finite in length, which implies not only that the past is finite but also that it has a first moment.

\section{Conclusion}

In this space I have traced the development of a particular line of argument for the finitude of the past that arose from Craig's modification of Russell's Tristram Shandy example and showed how its primary deficiency could be addressed by constructing a logically possible scenario concerning the diary-keeping activities of Methuselah as part of a new argument for the finitude of the past. Moreover, this argument can be naturally generalized to demonstrate not only that the past is finite but also that it has a first moment. 